ORIGINAL ARTICLE

\title{
Molecular and functional analysis identifies ALK-1 as the predominant cause of pulmonary hypertension related to hereditary haemorrhagic telangiectasia
}

\author{
R E Harrison, J A Flanagan, M Sankelo, S A Abdalla, J Rowell, R D Machado, C G Elliott, \\ I M Robbins, H Olschewski, V McLaughlin, E Gruenig, F Kermeen, T Laitinen, N W Morrell, \\ R C Trembath
}

J Med Genet 2003;40:865-871

\begin{abstract}
Background: Mutations of the transforming growth factor $\beta$ (TGF $\beta$ ) receptor components ENDOGLIN and ALK-1 cause the autosomal dominant vascular disorder hereditary haemorrhagic telangiectasia (HHT). Heterozygous mutations of the type II receptor BMPR2 underlie familial primary pulmonary hypertension. Objective: To investigate kindreds presenting with both pulmonary hypertension and HHT.

Methods: Probands and families were identified by specialist pulmonary hypertension centres in five countries. DNA sequence analysis of ALK-1, ENDOGLIN, and BMPR2 was undertaken. Cellular localisation was investigated by heterologous overexpression of mutant constructs in both BAEC and HeLa cells. The impact of a novel sequence variant was assessed through comparative analysis and computer modelling.

Results: Molecular analysis of 11 probands identified eight missense mutations of ALK-1, one of which was observed in two families. Mutations were located within exons 5 to 10 of the ALK-1 gene. The majority of $A L K-1$ mutant constructs appeared to be retained within the cell cytoplasm, in the endoplasmic reticulum. A novel GS domain mutation, when overexpressed, reached the cell surface but is predicted to disrupt conformational changes owing to loss of a critical hydrogen bond. Two novel missense mutations were identified in ENDOGLIN.

Conclusions: The association of pulmonary arterial hypertension and HHT identifies an important disease complication and appears most common among subjects with defects in ALK-1 receptor signalling. Future studies should focus on detailed molecular analysis of the common cellular pathways disrupted by mutations of $A L K-1$ and BMPR2 that cause inherited pulmonary vascular disease.
\end{abstract}

See end of article for authors' affiliations

Correspondence to: Professor Richard C Trembath, Division of Medical Genetics, Adrian Building, University of Leicester, University Road, Leicester LEl 7RH, UK; rtrembat@hgmp.mrc.ac.uk

Received 1 July 2003

Accepted 18 August 2003

$\mathrm{H}$ ereditary haemorrhagic telangiectasia (HHT), an autosomal dominant vascular dysplasia, is characterised clinically by recurrent epistaxis, mucocutaneous telangiectases, and systemic arteriovenous malformations of the lung, liver, and brain. Diverse heterozygous mutations in two genes, ENDOGLIN (ENG) and activin receptor-like kinase 1 $(A L K-1)$, cause HHT1 (MIM187300) and HHT2 (MIM 600376), respectively. ${ }^{12}$ Both ENG and ALK-1 encode receptor members of the transforming growth factor $\beta$ (TGF $\beta$ ) signalling superfamily, ALK-1 a type I receptor ${ }^{3}$ and endoglin, a so called accessory protein to the ligand receptor complex. ${ }^{4}$

Deleterious heterozygous mutations in the gene bone morphogenetic receptor type $2(B M P R 2)$, encoding a type II receptor member of the TGF $\beta$ family, have been identified in the majority of familial and up to $26 \%$ of sporadic cases of primary pulmonary hypertension (PPH-MIM 178600), a disorder of pulmonary arterial remodelling, ${ }^{5-7}$ and have also been reported in $9 \%$ of patients with pulmonary hypertension related to appetite suppressant exposure. ${ }^{8}$

BMPR-II, endoglin, and ALK-1 are membrane bound receptor members of the TGF $\beta$ signalling superfamily, which controls diverse cellular processes including cell differentiation, proliferation, and apoptosis in embryonic and mature tissues. ${ }^{9}$ Activation of the TGF $\beta$ pathway follows ligand binding and complex formation with type I and type II serine/ threonine receptors at the cell surface. This process can be facilitated by accessory receptors, such as endoglin, interacting with the ligand-receptor complex, as occurs in ALK-1 heteromeric complex formation in endothelial cells.
Intracellular signalling is propagated by receptor complexes phosphorylating specific groups of receptor regulated Smads (R-Smads), which complex with the comediator Smad 4 and are translocated to the nucleus to target transcriptional regulation of a restricted range of genes, in a cell type and context specific nature (reviewed by Shi and Massague ${ }^{9}$.

Significant progress in understanding the structural and functional requirements of the TGF $\beta$ pathway has been gained through the identification of human disease-causing mutations in genes encoding these proteins, generating hypotheses for the interplay between components of this complex signalling pathway-for example, in the control, development, and integrity of the vascular bed. ${ }^{9}$

The recent observation that pulmonary arterial hypertension, with clinical and histological features indistinguishable from primary pulmonary hypertension, may develop in HHT families supports the hypothesis that disruption of the TGF $\beta$ pathway is central to the development of pulmonary hypertension. ${ }^{10}$

In this paper we describe a cohort of 14 independently ascertained probands, 13 of whom presented with clinical features of pulmonary hypertension together with either a personal or family history of HHT. We have undertaken molecular analysis of the $A L K-1, E N G$, and BMPR2 genes, and investigated the functional impact of mutations identified. The findings show the importance of ALK-1 mediated signalling in the maintenance of the pulmonary vasculature, identify a novel molecular defect of type I TGF $\beta$ signalling in 
disease, and establish pulmonary hypertension as an important complication of HHT.

\section{METHODS}

\section{Patients}

Patients with a personal or family history of HHT and pulmonary hypertension were recruited from centres specialising in the treatment of this condition in England, Germany, Australia, and the USA. Patients were classified as having a probable or definite diagnosis of HHT according to the Curaçao criteria. ${ }^{11}$ In addition, a population based cohort of 21 Finnish subjects diagnosed with primary pulmonary hypertension was screened for mutations in $A L K-1, B M P R 2$, and ENG. Pulmonary hypertension was defined by standard clinical methods, including cardiac catheterisation $(n=13)$, as described previously. ${ }^{10}$ One subject was investigated by echocardiography alone (see table 1 for details).

All studies were done after informed consent had been obtained and with the approval of the Trent multi-research ethics committee or the relevant institutional review board.

\section{DNA sequence analysis}

The protein coding sequence of $A L K-1$ (exons 2-10, primers as previously described ${ }^{13}$ ), ENG (exons 1-13, primers available on request), and $B M P R 2$ (exons $1-13$, primers available on request) together with intron-exon boundaries were amplified from genomic DNA by polymerase chain reaction (PCR). PCR products were purified using the QIAquick purification kit (Qiagen) and sequenced with the Applied Biosystems Big Dye terminator kit and the ABI PRISM 377.

Sequence variants that altered restriction enzyme sites were confirmed by restriction digest of PCR amplified products according to the manufacturer's instructions, with fragments visualised on $2 \%$ agarose gels containing ethidium bromide.

Control chromosomes $(n=150)$ were examined for the presence of the identified sequence variants. In view of its distinct genetic heritage, a further 120 chromosomes, from unrelated unaffected subjects from Finland, were also examined specifically for the presence of the D179A mutation.

\section{Structural modelling of ALK-1}

Homology modelling techniques were used to generate the three dimensional structure of the ALK-1 kinase and GS domain, based on the crystal structure of the homologous type I TGF $\beta$ receptor ALK-5, as described previously. ${ }^{14}$ The SwissPDB program was used to examine the impact of D179A missense mutation in the GS domain of ALK-1 on the model. The respective amino acid side chains of D179 were altered to correspond to those of Al79, and potential alterations in the hydrogen bonding scheme or the presence of induced steric clashes were considered.

Table 1 Clinical details of patient cohort and identified ALK-1 mutations

\begin{tabular}{|c|c|c|c|c|c|c|c|c|c|c|c|c|c|c|}
\hline & \multicolumn{14}{|c|}{ Patient number } \\
\hline & $\mathrm{Cl}$ & $\mathrm{C} 2$ & C3 & 7685 & 7340 & 7242 & 7253 & 8261 & 7682 & 8259 & 7252 & 7214 & 7684 & 8151 \\
\hline Sex & $\mathrm{F}$ & $\mathrm{F}$ & $\mathrm{F}$ & $\mathrm{F}$ & $\mathrm{F}$ & $\mathrm{F}$ & $\mathrm{F}$ & $\mathrm{F}$ & $\mathrm{F}$ & $\mathrm{F}$ & $\mathrm{F}$ & M & M & $\mathrm{F}$ \\
\hline \multicolumn{15}{|l|}{ Status, age } \\
\hline (years) & A, 80 & $D, 16$ & $D, 65$ & $D, 54$ & A, 56 & A, 44 & NK & A, 41 & $D, 18$ & A, 29 & A, 26 & A, 49 & A, 62 & A, 64 \\
\hline HHT FH & Y & Y & Y & $\mathrm{N}$ & Y & Y & $\mathrm{Y}$ & Y & Y & Y & Y & $\mathrm{N}$ & Y & Y \\
\hline Epistaxis & $\mathrm{Y}$ & $\mathrm{Y}$ & $\mathrm{Y}$ & $\mathrm{N}$ & Y & $\mathrm{Y}$ & $\mathrm{Y}$ & Y & $\mathrm{N}$ & $\mathrm{Y}$ & Y & Y & Y & $\mathrm{N}$ \\
\hline Telangiectasia & $Y$ & $Y$ & $Y$ & $\mathrm{~N}$ & $Y$ & Y & $Y$ & $Y$ & $\mathrm{~N}$ & $Y$ & $Y$ & $Y$ & $\mathrm{Y}$ & $Y$ \\
\hline AVM & $\mathrm{N}$ & $\mathrm{N}$ & $\mathrm{N}$ & $\mathrm{N}$ & $N$ & Lung & $\mathrm{N}$ & $N$ & $\mathrm{~N}$ & $\mathrm{~N}$ & $\mathrm{~N}$ & $\mathrm{~N}$ & Lung & Lung liver \\
\hline onset (years) & 77 & 7 & 51 & 51 & 50 & 39 & 19 & 39 & 17 & 27 & 21 & 46 & 57 & 59 \\
\hline MPAP $(\mathrm{mm} \mathrm{Hg})$ & 54 & 55 & 47 & 55 & & 54 & 49 & 44 & 48 & 40 & 54 & 71 & 48 & 41 \\
\hline $\mathrm{CO}(\mathrm{l} / \mathrm{min})$ & 3.4 & NK & 4.8 & 2.5 & & 5.9 & 4.2 & 4.9 & 1.8 & 3.1 & NK & 4.8 & 6.7 & 7.0 \\
\hline $\mathrm{Cl}\left(1 / \mathrm{min} / \mathrm{m}^{2}\right)$ & 2.1 & 3.2 & 2.8 & NK & $E$ & 3.0 & & 3.0 & 1.3 & 1.8 & NK & 2.5 & 3.8 & 4.0 \\
\hline \multicolumn{14}{|c|}{ PVR (resistance } & 17 \\
\hline units) & 12.4 & 20.3 & 7.7 & 18 & & 7.1 & 9.3 & 6.9 & NK & 11.9 & 9.2 & 11.6 & 5.7 & 3.4 \\
\hline \multicolumn{15}{|l|}{ Vasodilator } \\
\hline response & $Y$ & $\mathrm{~N}$ & $\mathrm{~N}$ & $\mathrm{~N}$ & & $\mathrm{~N}$ & $\mathrm{~N}$ & $\mathrm{~N}$ & $\mathrm{~N}$ & $\mathrm{~N}$ & $\mathrm{~N}$ & $\mathrm{~N}$ & $\mathrm{~N}$ & ND \\
\hline $\begin{array}{l}\text { Treatment } \\
\text { Possible risk } \\
\text { factors }\end{array}$ & $C, B$ & C & $P$ & $P$ & $\begin{array}{l}P, B \\
A S\end{array}$ & $P$ & $P$ & \multicolumn{2}{|c|}{$\begin{array}{l}\text { S } \\
\text { Repaired } \\
\text { ASD, FH- } \\
\text { PPH }\end{array}$} & $P, B$ & $\mathrm{~T}$ & C & \multicolumn{2}{|l|}{$\begin{array}{l}\text { B, S } \\
P E\end{array}$} \\
\hline \multicolumn{15}{|l|}{ Mutation } \\
\hline Gene & & & & $A L K-1$ & $A L K-1$ & $A L K-1$ & $A L K-1$ & $A L K-1$ & $A L K-1$ & $A L K-1$ & $A L K-1$ & $A L K-1$ & ENG & ENG \\
\hline Exon & & & & 5 & & 7 & & 8 & 8 & & 8 & & & 10 \\
\hline Nucleotide & ND & ND & ND & 536 & 632 & 1031 & 1031 & 1120 & 1121 & 1196 & 1232 & 1460 & del 682 & delT \\
\hline change & - (no DNA) & - (no DNA) & - (no DNA) & $A>C$ & $G>A$ & $G>A$ & $G>A$ & $C>T$ & $G>A$ & $G>C$ & $G>A$ & $A>C$ & -686 & 1334 \\
\hline Amino acid & & & & D179A & G211D & C344Y & C344Y & R374W & R374Q & W399S & R411Q & K487T & S228fs+ & M445fs \\
\hline & & & & & & & & & & & & & $\begin{array}{l}\text { 102AA } \\
331 X\end{array}$ & $\begin{array}{l}+44 \mathrm{AA} \\
490 \mathrm{X}\end{array}$ \\
\hline $\begin{array}{l}\text { Restriction } \\
\text { enzyme }\end{array}$ & & & & Msc I & $B g / I$ & - & - & - & - & - & Hpa II & Mbo II & - & - \\
\hline Previous reports & & & & Novel & Novel & 12 & 12 & 131415 & 14 & Novel & 2131416 & Novel & Novel & Novel \\
\hline \multicolumn{15}{|c|}{ 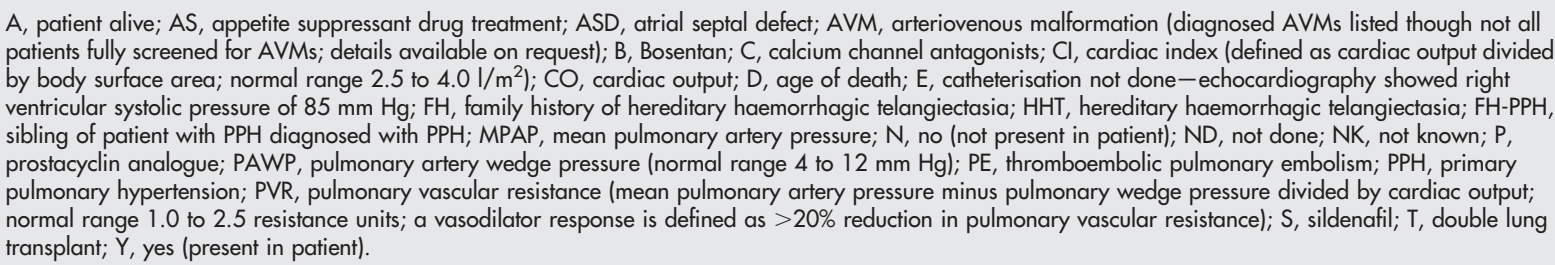 } \\
\hline
\end{tabular}




\section{Preparation of ALK-1 constructs}

The pT7T3DPac I.M.A.G.E clone (ID 2345585)—which contained all of the $A L K-1$ coding sequence (1509 bp), 82 base pairs (bp) of the $5^{\prime}$ untranslated region (UTR), and $145 \mathrm{bp}$ of the $3^{\prime}$ UTR-was inserted into pcDNA3 expression vector using Hind III and EcoR I. To generate the 3' GFP-ALK-1 wild type construct, the stop codon and 3' UTR were removed by PCR using forward primer 5' CTA GCT GTG TCC GCG GCA TGC GGC CTG 3' (Sac II restriction site underlined) with reverse primer 5' CAG AAT TCC GGA TCC GCT TGA ATC ACT TTA GG 3' (EcoR I and BamH I restriction sites bold and underlined, respectively). The pcDNA3-ALK-1 and PCR products were both digested with Sac II and EcoR I and ligated. The entire coding region of ALK-1 (with its 5' UTR) was then removed by digestion from pcDNA3 with Hind III and $B a m \mathrm{H} \mathrm{I}$, and the $1591 \mathrm{bp}$ fragment was inserted into Hind III/BamH I digested pEGFPNI vector (Clontech). The presence of a signal peptide in ALK-1 prevented the direct GFP tagging of the $5^{\prime}$ end of the protein. Using PCR and a three step cloning strategy (full details available on request) a myc-tag was inserted between the signal peptide and the mature protein.

Mutant constructs were generated by subjecting both wild type constructs to site directed mutagenesis using the Stratagene QuikChange protocol. The sequences of the wild type and mutant constructs were confirmed by DNA sequencing of the entire receptor with GFP or myc tag as appropriate.

\section{Subcellular localisation of ALK-1}

Bovine aortic endothelial cells (BAEC) or HeLa cells were seeded on glass coverslips in six-well plates at $2 \times 10^{5}$ or $4 \times 10^{5}$ cells per well, respectively, and grown for 24 hours in DMEM/10\% fetal calf serum. One microgram of wild type or mutant construct was used to transiently transfect cells using $3 \mu \mathrm{l}$ of the FuGene (Roche) transfection reagent system. Transfectants were grown for another 48 hours, then fixed in $4 \%$ paraformaldehyde in phosphate buffered saline (PBS). Cells were permeabilised with $0.4 \%$ ( $\mathrm{vol} / \mathrm{vol}$ ) Triton-X for four minutes before immunostaining of myc-tagged constructs or endoplasmic reticulum. Myc tagged transfectants were incubated with the anti-myc monoclonal primary antibody (9E10) at a dilution of 1 in 250 in a 3\% solution of bovine serum albumin (BSA) for one hour. To visualise the endoplasmic reticulum, cells were incubated with the KDEL monoclonal primary antibody (Stressgen Biotechnologies) at a dilution of 1 in 250 ( $\mathrm{vol} / \mathrm{vol})$ in 3\% BSA for one hour. Subsequent incubations for both primary antibodies were with biotinylated anti-mouse IgG antibody (Amersham) for one hour at a 1 in 100 dilution in 3\% BSA, followed by Streptavidin Texas Red (Amersham) at a 1 in 200 dilution in 3\% BSA for 45 minutes. Coverslips were mounted on microscope slides in glycerol/PBS solution. Cells were viewed and photographed using a fluorescent microscope (Zeiss) and images captured using SmartCapture 2 software.

Transfection efficiency for GFP and myc-tagged constructs was approximately $30 \%$ in HeLa cells, and 5\% in BAEC.

\section{RESULTS}

Clinical details and investigative findings in the 14 probands are summarised in table 1. Twelve subjects were recruited by centres in England, Germany, Australia, and the USA. Two further probands (7685 and 7682) were identified in a cohort of Finnish patients with primary pulmonary hypertension, with full details of this series described elsewhere (manuscript submitted).

Twelve patients presented with haemodynamic evidence of pulmonary arterial hypertension unexplained by a hyperdynamic circulation, a syndrome we now describe as HHT related pulmonary arterial hypertension. For two of these subjects, additional recognised risk factors for pulmonary arterial hypertension were identified. Subject 8261 had an atrial septal defect repaired before the onset of significantly raised pulmonary artery pressures, and also had a sibling diagnosed with primary pulmonary hypertension who had plexogenic pulmonary vascular changes at necropsy. Patient 7340 gave a history of six months' exposure to an appetite suppressant, at least eight years before the onset of symptoms.

In contrast, two further subjects with HHT and raised pulmonary artery pressures had clear evidence of other causes of pulmonary hypertension. In patient 8151, haemodynamic studies reveal a raised mean pulmonary artery pressure associated with a minimally raised pulmonary vascular resistance, findings consistent with a hyperdynamic circulation probably caused by extensive systemic arteriovenous malformations. Finally, subject 7684 developed pulmonary hypertension following massive thromboembolic disease. No material was available for DNA analysis in three families presenting with clinical or histological features of HHT related pulmonary arterial hypertension.

\section{Molecular genetic analysis}

A heterozygous mutation of $A L K-1$ was identified in nine probands, each with HHT related pulmonary arterial hypertension, of which the C344Y mutation was detected in two independently ascertained probands (from Germany and the USA) and has also been reported previously. ${ }^{12}$ Four of the eight $A L K-1$ mutations are novel and each represents a missense change (table 1). With one exception, each substitution is located within the kinase domain and alters an amino acid that is highly conserved across type I members of the TGF $\beta$ receptor family and between species for which sequence is available (fig 1). The D179A substitution is located within the GS region, a helix-loop-helix structure proximal to the kinase domain. Heterozygous mutations of ENG were identified in two subjects (7684 and 8151), each representing a novel frameshift mutation and predicted to lead to premature truncation of the transcript. None of the mutations was identified among appropriate matched control groups.

\section{Structural modelling}

The ALK-1 catalytic kinase domain is predicted to contain a small N-lobe and a larger, mostly helical C-lobe. The aspartic acid residue at position 179 is located in the $\alpha \mathrm{GS} 1$ helix of the GS domain of the small N-lobe (fig 2A). Substitution of aspartic acid 179 by alanine replaces an acidic residue with a neutral, weakly hydrophobic residue. One of the two hydrogen bonds to Arg252 is destroyed (fig 2B).

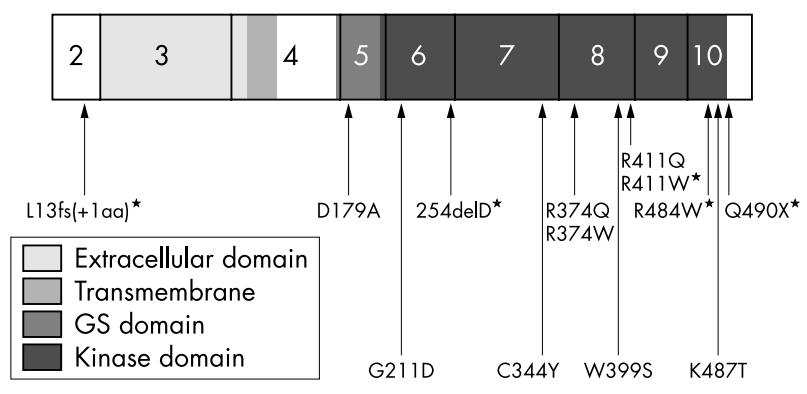

Figure 1 ALK-1 cDNA with mutations identified in patients with $\mathrm{HHT}$ related pulmonary arterial hypertension; mutations previously reported ${ }^{10}$ indicated by an asterisk. 
A

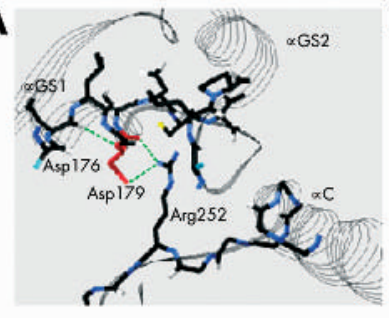

Asp179

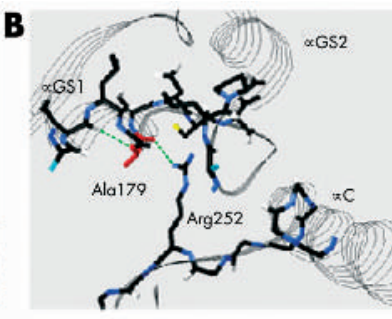

Ala179
C

Aspartic acid(D) 179Alanine(A)

Figure 2 Potential disruption of the GS domain of ALK-1 resulting from the substitution of aspartic acid residue 179 with alanine. (A) Aspartic acid (Aspl79 shown in red) forms two strong hydrogen bonds ( $\mathrm{H}$-bonds) to arginine 252 (Arg 252). (B) Substitution of Aspl79 with an uncharged alanine residue (Ala179 shown in red) destroys one of these two $\mathrm{H}$-bonds (calculated using Swiss PDB program). Carbon atoms are represented by black bars, oxygen by white bars, hydrogen by turquoise, sulphur by yellow, nitrogen by blue, and strong $\mathrm{H}$ bonds are shown in green. $\alpha \mathrm{GS1} / 2$ denotes the $\alpha \mathrm{GS}$ helices of the GS domain, and $\alpha \mathrm{C}$ the $\alpha \mathrm{C}$ helix of the $\mathrm{N}$ lobe of the kinase domain. (C) Conservation of amino acid residue Asp179.

\section{Subcellular localisation of ALK-1}

To investigate the impact of mutation of $A L K-1$ on protein localisation, we carried out transient transfection of either GFP $(n=11)$ or myc $(n=9)$ tagged mutant constructs. A range of mutant constructs was designed to include mutations of different classes from all known functional domains of ALK-1, and hence includes mutations identified in this and previous studies (table 2). Mutant constructs with myc tags located in a $5^{\prime}$ position were used to investigate truncating mutations and to confirm that the presence of the large 3' GFP tag did not impede protein trafficking. Both GFP and myc-tagged wild type ALK-1 constructs reached the cell surface (fig 3A). Only three $A L K-1$ mutations generated

proteins capable of targeting the cell surface appropriately when overexpressed (fig 3B). Two of these, D179A and $\mathrm{K} 487 \mathrm{~T}$, were characterised in subjects with pulmonary hypertension. The 12 further $A L K-1$ mutations appeared to be retained in the cell cytoplasm and colocalised with KDEL staining of the endoplasmic reticulum (fig 3C, 3D, and 3E).

\section{DISCUSSION}

Hereditary haemorrhagic telangiectasia and familial primary pulmonary hypertension represent inherited disorders of the vascular system caused by mutation of components of the TGF $\beta$ receptor mediated signalling system. We have identified a cohort of 14 subjects with pulmonary hypertension of whom 13 had a documented personal and/or family history of HHT. Among 11 probands in whom molecular analysis was possible, eight distinct mutations of the TGF $\beta$ type I receptor ALK-1 were identified in nine subjects. The two remaining subjects were found to harbour novel heterozygous mutations in the gene encoding the TGF $\beta$ accessory protein endoglin.

Clinical findings in these patients illustrate the complex aetiology of pulmonary hypertension in individuals with HHT. Pulmonary hypertension has typically been described in HHT as a consequence of high blood flow through large arteriovenous malformations leading to an increased cardiac output, often with evidence of left ventricular failure. ${ }^{20}$ These findings are illustrated by patient 8151 in the present series, who was found to have a novel ENG mutation and in whom hepatic blood flow through extensive liver arteriovenous malformations was estimated to exceed four litres a minute. However, most subjects in this cohort have HHT related pulmonary arterial hypertension as we have previously described..$^{10}$ In this syndrome pulmonary hypertension is characterised by a significantly raised pulmonary artery pressure, with high pulmonary vascular resistance, normal pulmonary artery wedge pressure, and a normal or low cardiac output. Importantly, all patients fulfilling these criteria were found to have $A L K-1$ mutations.

Of the eight $A L K-1$ mutations identified in this study, four appear to be novel, bringing the total number of disease causing defects reported in the $A L K-1$ gene to $54 .^{21}$ Taken together with our initial report of HHT related pulmonary

Table 2 Range of ALK-1 mutant constructs transiently transfected into HeLa and bovine aortic endothelial cells, with subcellular localisation

\begin{tabular}{|c|c|c|c|c|c|c|}
\hline \multirow[b]{2}{*}{$\begin{array}{l}\text { ALK-1 } \\
\text { mutation }\end{array}$} & \multirow[b]{2}{*}{$\begin{array}{l}\text { Location of } \\
\text { mutation }\end{array}$} & \multicolumn{2}{|c|}{$\begin{array}{l}\text { Mutant ALK-1 } \\
\text { constructs produced }\end{array}$} & \multicolumn{2}{|c|}{$\begin{array}{l}\text { Reported phenotype in present } \\
\text { series }\left(^{*}\right) \text { or previous studies }\end{array}$} & \multirow[b]{2}{*}{ Localisation } \\
\hline & & $\begin{array}{l}\text { Myc } \\
\text { tagged }\end{array}$ & $\begin{array}{l}\text { GFP } \\
\text { tagged }\end{array}$ & Phenotype & Reports & \\
\hline G48E;A49P† & $\begin{array}{l}\text { Extracellular } \\
\text { domain }\end{array}$ & $\checkmark$ & & HHT only & 12 & Intracellular \\
\hline W50C & $\begin{array}{l}\text { Extracellular } \\
\text { domain }\end{array}$ & $\checkmark$ & $\checkmark$ & HHT only & 121317 & Intracellular \\
\hline R67Q & $\begin{array}{l}\text { Extracellular } \\
\text { domain }\end{array}$ & & $\checkmark$ & HHT only & 1013 & Intracellular \\
\hline C77W & $\begin{array}{l}\text { Extracellular } \\
\text { domain }\end{array}$ & $\checkmark$ & $\checkmark$ & HHT only & 17 & Intracellular \\
\hline DI79A & GS domain & & $\checkmark$ & HHT with PAH & Novel $^{*}$ & Cell surface \\
\hline G211D & Kinase domain & & $\checkmark$ & HHT with PAH & Novel $^{*}$ & Intracellular \\
\hline delS232 & Kinase domain & $\checkmark$ & $\checkmark$ & HHT only & 21213 & Cell surface \\
\hline delD254 & Kinase domain & 2 & & HHT with PAH & 10 & Intracellular \\
\hline S333! & Kinase domain & & $\checkmark$ & HHT only & 12131418 & Intracellular \\
\hline C344Y & Kinase domain & $\checkmark$ & 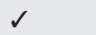 & HHT with PAH & $12 *$ & Intracellular \\
\hline$R 374 Q$ & Kinase domain & & $\checkmark$ & HHT with PAH & $14 *$ & Intracellular \\
\hline P378L & Kinase domain & $\checkmark$ & & HHT only & & Intracellular \\
\hline R411Q & Kinase domain & & 2 & HHT with PAH & $2131416 *$ & Intracellular \\
\hline K487T & Kinase domain & $\checkmark$ & 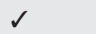 & HHT with PAH & Novel* $^{*}$ & Cell surface \\
\hline Q490X & Kinase domain & 2 & & HHT with PAH & & Intracellular \\
\hline
\end{tabular}



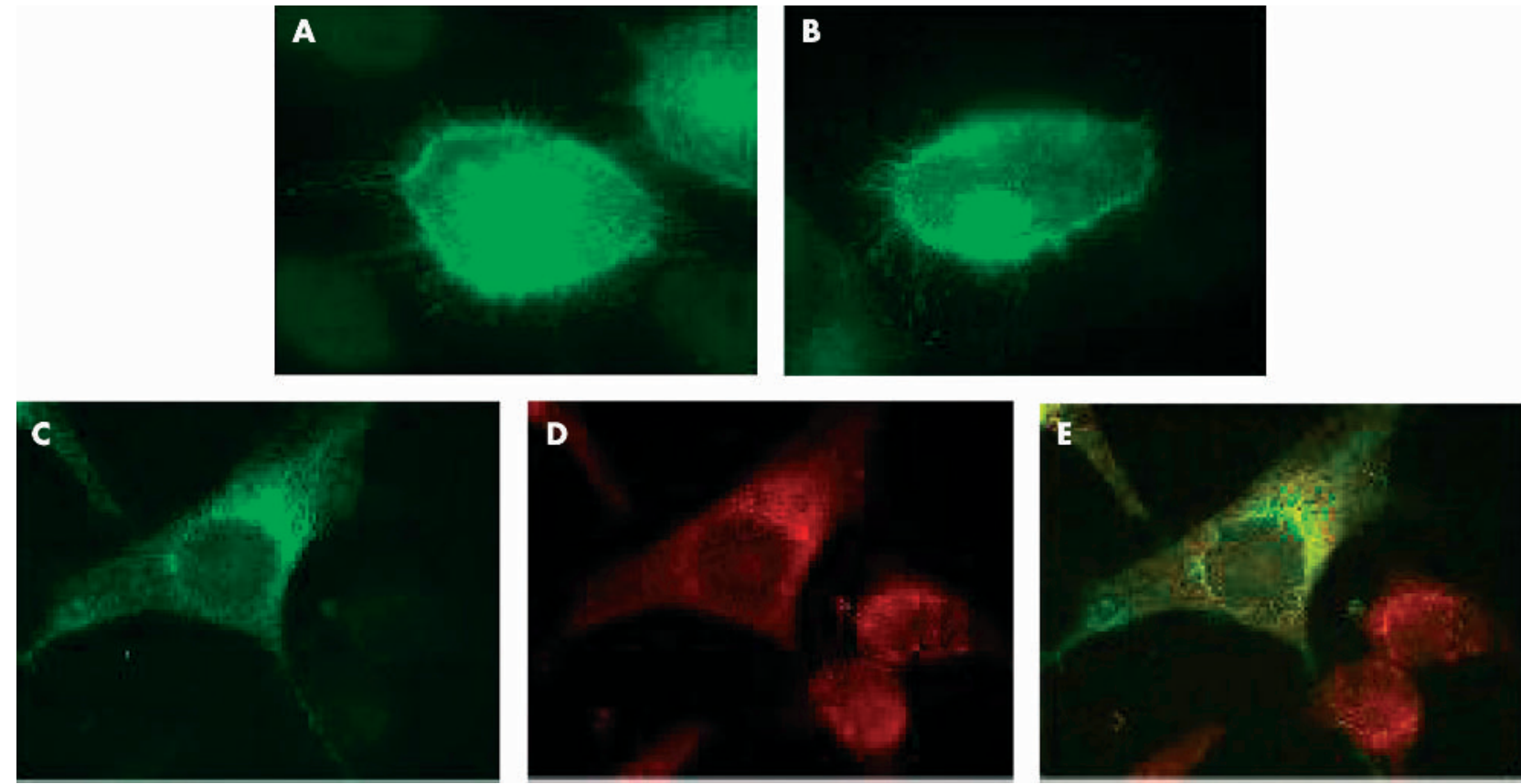

Figure 3 Immuofluorescence microscopy of HeLa and BAEC cells transiently transfected with GFP tagged wild type mutant constructs. (A) Wild type GFP tagged ALK-1 construct showing cell surface localisation. (B) Representative of GFP tagged mutant constructs D179A, del S232, K487T showing cell surface localisation comparable to wild type. (C) Representative of GFP tagged ALK-1 mutant constructs G48E;A49P, W50C, R67Q, C77W, G21 1D, delD254, S333I, C344Y, R374Q, P378L, R41 1Q, Q490X showing intracellular localisation. (D) Endoplasmic reticulum immunostained with anti-KDEL antibody (red). (E) Superimposition of KDEL (red) and GFP signals clearly shows endoplasmic reticulum localisation of mislocalised mutants (yellow).

arterial hypertension, ${ }^{10} 13$ ALK-1 mutations (24\%) have been characterised in probands with HHT related arterial pulmonary hypertension, emphasising the importance of this complication in HHT2. All the mutations identified are missense changes and were not detected among controls. Seven of the eight $A L K-1$ mutations reported alter highly conserved amino acids within the functional kinase domain of the type I receptor. ${ }^{13}$ Of these, two mutations (R374W and R374Q) substitute arginine at codon 374 with tryptophan or glutamine, respectively. The mutation R411Q, also in exon 8 , and the mutation R41 $1 \mathrm{~W}$ identified in the previous series, ${ }^{10}$ both replace arginine with glutamine or tryptophan. In all, five mutations in exon 8 have been identified among subjects with HHT related pulmonary arterial hypertension, more than any other region of the $A L K-1$ gene. Identification of recurrent sites of mutation within exon 8 identifies critical regions for kinase activity mediating the ALK-1 receptor cellular response in vascular development and repair. Of interest, the $A L K-1$ mutation $\mathrm{C} 344 \mathrm{Y}$, which has previously been reported to cause HHT, was detected in two probands independently ascertained through centres in Germany and the USA. Genealogical information failed to identify a common ancestor, and relatives were not available for conclusive haplotype analysis. The exon 10 mutation, K487T, represents the most distal missense substitution thus far identified and falls within the highly conserved $\mathrm{COOH}$ domain of ALK-1. The region, from codons 479 to 489 contains a so called NANDOR BOX which appears to be necessary for regulation of TGF $\beta$ signalling. ${ }^{22}$ Taken together with the previous report of the R484W mutation, ${ }^{10}$ these findings imply important structural requirements for this domain and suggest that perturbation of these may critically affect the NANDOR BOX activity, particularly with regard to the pulmonary vasculature

The D179A mutation (exon 5) identified in a patient with primary pulmonary hypertension without known features of
HHT is of particular interest. The patient died recently in Finland, aged 54 years, and retrospective analysis confirmed the diagnosis of primary pulmonary hypertension, but no mention was made in the case history or at necropsy of either the symptoms (for example, epistaxis) or the pathological features (arteriovenous malformations) of HHT. The mutation was not detected among a further group of control subjects $(n=60)$ recruited from the same region of Finland. Parents or surviving relatives were not available for study. The $A L K-1$ mutation leads to an amino acid substitution of aspartic acid by alanine at codon 179 which is conserved across species and type I receptors and lies within the so called GS domain, a serine and threonine residue rich region (fig 2C). The GS domain is critical for regulation of receptor activity-for example, the immunophilin FKBP12 inhibits TGF $\beta$ signalling by competitive binding to unphosphorylated GS residues of the type I receptor, which also maintains the kinase domain in an inactive state. ${ }^{23}$ In contrast, phosphorylation has been shown, at least for T $\beta R 1$, to "switch" the GS domain into a binding surface for R-Smads and significantly increase the efficiency of receptor mediated phosphorylation of C-terminal serine Smad residues. ${ }^{24}$ Overexpression studies of a GFP fusion protein for the D179A mutation demonstrated localisation to the cell surface, implying that the mutation does not lead to significant protein misfolding. Structural modelling, however, showed that the substitution of aspartic acid (a polar acidic amino acid) for alanine (a nonpolar weakly hydrophobic amino acid) results in the loss of a hydrogen bond formed with an arginine at position 252, a residue critical for GS-kinase domain interaction (fig $2 \mathrm{~A}$ and $2 \mathrm{~B})$. No disease related mutations of the GS region had hitherto been reported. ${ }^{21}$ Thus the present findings suggest a novel form of molecular defect in TGF $\beta$ signalling associated with the development of pulmonary hypertension.

The coexistence of HHT, a disorder characterised by dilation of arteriovenous communications and pulmonary 
hypertension caused by occlusion and abnormal remodelling of vessels specifically within the pulmonary vasculature, is unexpected and suggests that a common molecular pathway may underlie both disorders. To date, subjects with HHT related pulmonary arterial hypertension have only been shown to harbour $A L K-1$ mutations, though it remains unclear whether this reflects molecular specificity, as the number of kindreds reported, in total 14, remains small. ${ }^{10} \mathrm{~A}$ direct interaction between BMPR-II encoded by the gene mutated in familial primary pulmonary hypertension, and ALK- 1 has yet to be identified, and they are not activated by the same class of ligands. ${ }^{9}$ In contrast, both receptors are known to mediate intracellular signalling through the Smads 1,5 , and 8 , and mutations identified in this and our previous study are all likely to disrupt activation of this intracellular pathway. There is extensive molecular heterogeneity for disease causing mutations of $A L K-1$; however, most of the defects leading to HHT related pulmonary arterial hypertension appear to be missense mutations and all affect discrete cytoplasmic domains of the protein. ${ }^{10}$

To investigate further the potential functional differences between known pathogenic $A L K-1$ mutations, we undertook heterologous overexpression studies of both ligand binding and cytoplasmic domain mutations. We observed that the majority of all mutations failed to reach the cell surface, presumably as a result of significant protein misfolding..$^{25}$ These findings were consistent when studied using myc or GFP tagged mutant constructs. Thus initial functional analysis provides no evidence to distinguish those $A L K-1$ mutations associated with pulmonary hypertension. Taken together with a previous report of protein expression in vivo in HUVEC samples from HHT2 families, ${ }^{12}$ these data support haploinsufficiency as the inherited mechanism for this disorder. Further functional analysis of downstream ALK-1 signalling is substantially hampered by difficulties in producing an adequate in vitro representation of its signalling complex; hence we cannot rule out dominant negative effects of some mutations, and in particular those shown to reach the cell surface (D179A, delS232, and K487T).

Although marked clinical variability exists both within and between families, current data show that clinical manifestations of ALK-1 mediated HHT are observed with high penetrance by the age of 40 years. ${ }^{182627}$ ALK-1 defects less commonly lead to HHT related pulmonary arterial hypertension. In familial primary pulmonary hypertension, we know that pathogenic mutations in BMPR2 are required but are not sufficient for the development of disease, with many instances of non-penetrance described. ${ }^{28}{ }^{29}$ Taken together, these data indicate a need for exposure to as yet unknown "trigger" factors, in addition to a genetic susceptibility. In this regard it is of interest that patient 7340 gave a history of exposure to appetite suppressants, a known risk factor for the development of pulmonary hypertension. It is unclear whether exposure to appetite suppressants was causal of disease in this patient. The molecular basis for an interaction between appetite suppressant exposure and a genetic susceptibility generated by defects in BMPR2 or ALK-1 requires further study. ${ }^{8}$ A recent report of a patient harbouring a pathogenic ENG mutation developing pulmonary hypertension following documented fenfluramine exposure (Soubrier F, personal communication) neither resolves nor detracts from the hypothesis that such an interaction may occur. It is of interest that among this present series, selected on the basis of patient referral with HHT and pulmonary hypertension, we only detected $E N G$ mutations in patients with causes for raised pulmonary artery pressures that were distinct from pulmonary hypertension. Hence the role of the accessory protein endoglin in predisposing to pulmonary hypertension must await further assessment, including a search for subjects with $E N G$ mutations and the syndrome of HHT related pulmonary arterial hypertension, in the absence of other recognised and potentially independent risk factors.

It is clear that pulmonary hypertension is an important and not infrequent complication of ALK-1 mediated disease. HHT should also be considered, and may require screening for, in patients presenting with apparent primary pulmonary hypertension. For example, a girl (7682) with no personal history of HHT but whose mother was affected developed severe pulmonary hypertension at age 17 years and died within 12 months. Finally, and to further emphasise the complex management issues in this group of disorders, patient 7684 was identified as having endoglin mediated HHT and developed pulmonary hypertension secondary to massive thromboembolic disease, showing that other causes of pulmonary hypertension may also coexist in HHT patients.

The identification of human mutations in receptor components of the TGF $\beta$ receptor and vascular disease has provided important targets for further investigation and understanding of vasculogenesis and blood vessel response to injury. Analysis of specific patient cohorts offers additional insight into the functional requirements and specificity of these pathways but also has important implications for the long term management of families with such inherited disorders.

\section{Note added in proof}

A recent study ${ }^{30}$ has reported a disease causing mutation in the GS domain of BMPRIB-another type 1 receptor in the TGF $\beta$ pathway.

\section{ACKNOWLEDGEMENTS}

We wish to thank all of the patients and their relatives who have kindly participated in this study. We additionally thank Claire Dixon and Rachel Marriott for technical and secretarial assistance, respectively. This work is supported by a BHF programme grant RG/2000012 (RCT and NWM) and in Finland by The Academy of Finland and The Finnish National Technology Agency Tekes. REH is the recipient of a BHF clinical fellowship.

\section{Authors' affiliations}

R E Harrison, J A Flanagan, J Rowell, R D Machado, R C Trembath,

Division of Medical Genetics, University of Leicester, Leicester, UK M Sankelo, T Laitinen, Department of Medical Genetics, University of Helsinki, Helsinki, Finland

S A Abdalla, Cancer and Blood Research Programme, The Hospital for Sick Children, Toronto, Canada

C G Elliott, Pulmonary Department, LDS Hospital, Salt Lake City, Utah, USA

I M Robbins, Division of Allergy, Pulmonary and Critical Care Medicine, Vanderbilt University Medical Center, Nashville, USA

H Olschewski, Department of Internal Medicine II, Justus Liebig University, Giessen, Germany

V McLaughlin, Rush-Presbyterian-St Luke's Medical Center, Chicago, Illinois, USA

E Gruenig, Department Internal Medicine III, University of Heidelberg, Germany

F Kermeen, Flinders Medical Centre, South Australia, Australia N W Morrell, Department of Medicine, University of Cambridge, UK M Halme, Department of Pulmonary Medicine, Helsinki University Hospital, Finland

A Räisänen-Sokolowski, Department of Pathology, Helsinki University Hospital, Finland

\section{REFERENCES}

1 McAllister KA, Grogg KM, Johnson DW, Gallione CJ, Baldwin MA Jackson CE, Helmbold EA, Markel DS, McKinnon WC, Murrell J. Endoglin, a TGF-beta binding protein of endothelial cells, is the gene for hereditary haemorrhagic telangiectasia type 1. Nat Genet 1994;8:345-51.

2 Johnson DW, Berg JN, Baldwin MA, Gallione CJ, Marondel I, Yoon SJ, Stenzel TT, Speer M, Pericak-Vance MA, Diamond A, Guttmacher AE, Jackson CE, Attisano L, Kucherlapati R, Porteus ME, Marchuk DA. Mutations in 
the activin receptor-like kinase 1 gene in hereditary haemorrhagic telangiectasia type 2. Nat Genet 1996;13:189-95.

3 Attisano L, Carcamo J, Ventura F, Weis FM, Massague J, Wrana JL. Identification of human activin and TGF beta type I receptors that form heteromeric kinase complexes with type II receptors. Cell 1993;75:671-80.

4 Pece-Barbara N, Wrana JL, Letarte M. Endoglin is an accessory protein that interacts with the signaling receptor complex of multiple members of the transforming growth factor-beta superfamily. J Biol Chem 1999;274:584-94.

5 International PPH Consortium: Lane KB Machado RD, Pauciulo MW, Thomson JR, Phillips JA, Loyd JE, Nichols WC, Trembath RC. Heterozygous germline mutations in BMPR2, encoding a TGF-beta receptor, cause familial primary pulmonary hypertension. The International PPH Consortium. Nat Genet 2000;26:81-4.

6 Deng Z, Morse JH, Slager SL, Cuervo N, Moore KJ, Venetos G, Kalachikiv S, Cayanis E, Fischer SG, Barst RJ, Hodge SE, Knowles JA. Familial primary pulmonary hypertension (gene PPHI) is caused by mutations in the bone morphogenetic protein receptor-II gene. Am J Hum Genet 2000;67:737-44.

7 Thomson JR, Machado RD, Pauciulo MW, Morgan NV, Humbert M, Elliott GC, Ward K, Yacoub M, Mikhail G, Rogers P, Newman J, Wheeler L, Higenbottam T, Gibbs JS, Egan J, Crozier A, Peacock A, Allcock R, Corris P, Loyd JE, Trembath RC, Nichols WC. Sporadic primary pulmonary hypertension is associated with germline mutations of the gene encoding BMPR-II, a receptor member of the TGF-beta family. J Med Genet 2000;37:741-5.

8 Humbert M, Deng Z, Simonneau G, Barst RJ, Sitbon O, Wolf M, Cuervo N, Moore KJ, Hodge SE, Knowles JA, Morse JH. BMPR2 germline mutations in pulmonary hypertension associated with fenfluramine derivatives. Eur Resp J 2002;20:518-23.

9 Shi Y, Massague J. Mechanisms of TGF-beta signaling from cell membrane to the nucleus. Cell 2003;113:685-700.

10 Trembath RC, Thomson JR, Machado RD, Morgan NV, Atkinson C, Winship I, Simonneau G, Galie N, Loyd JE, Humbert M. Nichols WC, Morrell NW Berg J, Manes A, McGaughran J, Pauciolo M, Wheeler L. Clinical and molecular genetic features of pulmonary hypertension in patients with hereditary hemorrhagic telangiectasia. N Engl J Med 2001;345:325-34.

11 Shovlin CL, Guttmacher AE, Buscarini E, Faughnan ME, Hyland RH, Westermann CJ, Kjeldsen AD, Plauch H. Diagnostic criteria for hereditary hemorrhagic telangiectasia (Rendu-Osler-Weber syndrome). Am J Med Genet 2000;91:66-7.

12 Abdalla SA, Pece-Barbara N, Vera S, Tapia E, Paez E, Bernabeu C, Letarte M. Analysis of ALK-1 and endoglin in newborns from families with hereditary hemorrhagic telangiectasia type 2. Hum Mol Genet 2000:9:1227-37.

13 Berg JN, Gallione CJ, Stenzel TT, Johnson DW, Allen WP, Schwartz CE, Jackson CE, Porteus ME, Marchuk DA. The activin receptor-like kinase 1 gene: genomic structure and mutations in hereditary hemorrhagic telangiectasia type 2. Am J Hum Genet 1997:61:60-7.

14 Abdalla SA, Cymerman U, Johnson RM, Deber CM, Letarte M. Diseaseassociated mutations in conserved residues of ALK-1 kinase domain. Eur J Hum Genet 2003:11:279-87.
15 Kieldsen AD, Brusgaard K, Poulson L, Kruse T, Rasmussen K, Green A, Vase P. Mutations in the ALK-1 gene and the phenotype of hereditary hemorrhagic telangiectasia in two large Danish families. Am J Med Genet 2001;98:298-302.

16 Lin WD, Wu JY, Hsu HB, Tsai FJ, Lee CC, Tsai CH. Mutation analysis of a family with hereditary hemorrhagic telangiectasia associated with hepatic arteriovenous malformation. J Formos Med Assoc 2001;100:817-19.

17 Klaus DJ, Gallione CJ, Anthony K, Yeh EY, Yu J, Lux A, Johnson DW Marchuk DA. Novel missense and frameshift mutations in the activin receptorlike kinase-1 gene in hereditary hemorrhagic telangiectasia. Mutations in brief no. 164. Online. Hum Mutat 1998;12:137.

18 McDonald JE, Miller FJ, Hallam SE, Nelson L, Marchuk DA, Ward KJ. Clinical manifestations in a large hereditary hemorrhagic telangiectasia (HHT) type 2 kindred. Am J Med Genet 2000;93:320-7.

19 Olivieri C, Mira E, Delu G, Pagella F, Zambelli A, Malvezzi L, Buscarini E, Danesino $C$. Identification of 13 new mutations in the ACVRL1 gene in a group of 52 unselected Italian patients affected by hereditary haemorrhagic telangiectasia. J Med Genet 2002;39:E39.

20 Sapru RP, Hutchinson DC, Hall Jl. Pulmonary hypertension in patients with pulmonary arteriovenous fistulae. Br Heart J 1969;31:559-69.

21 van den Driesche S, Mummery CL, Westermann CJ. Hereditary hemorrhagic telangiectasia: an update on transforming growth factor beta signaling in vasculogenesis and angiogenesis. Cardiovasc Res 2003:58:20-31.

22 Garamszegi N, Dore JJ, Penheiter SG, Edens M, Yao D, Leof EB. Transforming growth factor beta receptor signaling and endocytosis are linked through a $\mathrm{COOH}$ terminal activation motif in the type I receptor. Mol Biol Cell 2001;12:2881-93.

23 Huse M, Chen YG, Massague J, Kuriyan J. Crystal structure of the cytoplasmic domain of the type I TGF beta receptor in complex with FKBP12. Cell 1999;96:425-36.

24 Huse M, Muir TW, Xu L, Chen YG, Kuriyan J, Massague J. The TGF beta receptor activation process: an inhibitor- to substrate-binding switch. Mol Cell 2001:8:671-82

25 Rudarankanchana N, Flanagan JA, Chen H, Utpon PD, Machado RD, Patel D, Trembath RC, Morrell NW. Functional analysis of bone morphogenetic protein type II receptor mutations underlying primary pulmonary hypertension. Hum Mol Genet 2002;11:1-9.

26 Porteous ME, Burn J, Proctor SJ. Hereditary haemorrhagic telangiectasia: a clinical analysis. J Med Genet 1992;29:527-30.

27 Abdalla SA, Geisthoff UW, Bonneau D, Plauchu H, McDonald J, Kennedy S, Faughnan ME, Letarte $M$. Visceral manifestations in hereditary haemorrhagic telangiectasia type 2. J Med Genet 2003;40:494-502.

28 Loyd JE, Primm RK, Newman JH. Familial primary pulmonary hypertension: clinical patterns. Am Rev Respir Dis 1984; 129:194-7.

29 Thomas AQ, Gaddipati R, Newman JH, Loyd JE. Genetics of primary pulmonary hypertension. Clin Chest Med 2001;22:477-91.

30 Lehmann K, Seemann P, Stricker S, Sammar M, Meyer B, Süring K, Majewski F, Tinschert S, Grzeschik K, Müller A, Knaus P, Nürnberg P, Mundlos S. Mutations in bone morphogenic protein receptor 1B cause brachydactyly type A2. Proc Natl Acad Sci USA 2003;100:12277-82.

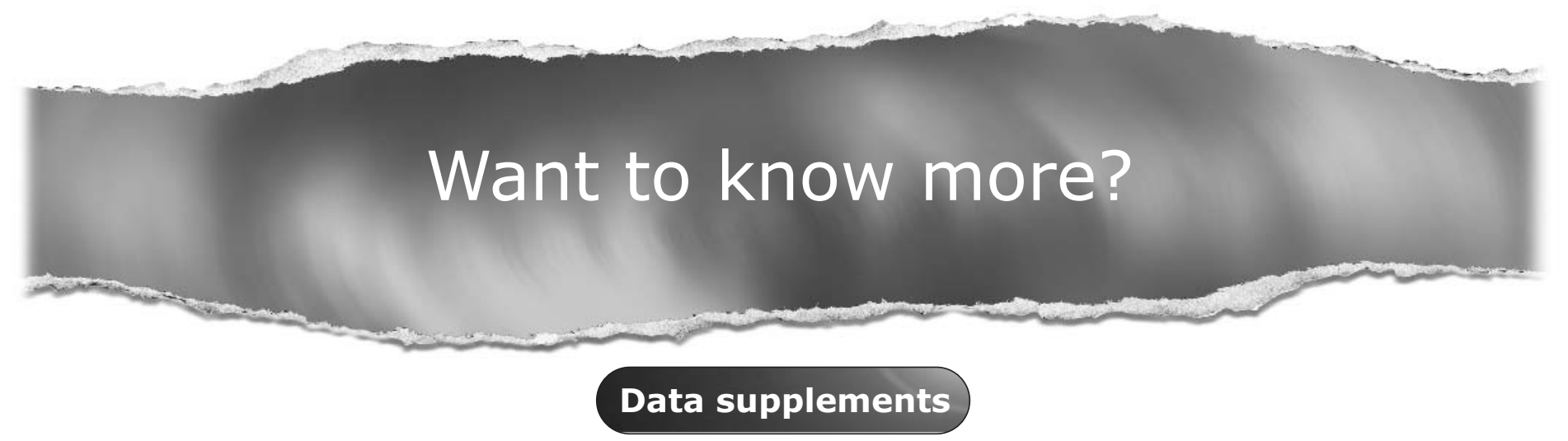

Limited space in printed journals means that interesting data and other material are often edited out of articles; however, limitless cyberspace means that we can include this information online.

Look out for additional tables, references, illustrations.

www.jmedgenet.com 


\section{PostScript}

\section{BOOK REVIEWS}

\section{Inborn errors of development: the molecular basis of clinical disorders of morphogenesis}

Edited by C J Epstein, R P Erickson, A Wynshaw-Boris. Oxford: Oxford University Press, 2003, £150, pp 1082. ISBN 0-19514502-X (hardback)

The third edition of David Smith's outstanding textbook, Recognizable patterns of human malformation, was published in 1982. It consisted of 652 pages with detailed descriptions of over 250 malformation syndromes. It was, and remains, an excellent book. Yet it did not contain a single mention of molecular pathogenesis or an underlying mutational spectrum.

How times have changed. Now, thanks to extraordinary developments in molecular biology, it is the exception rather than the rule to encounter a syndrome for which there is not an available molecular handle. The diverse fields of molecular genetics and clinical dysmorphology have pooled their intellectual responses to burrow away at the mysteries of human development. Their triumphant emergence is elegantly encapsulated in this wonderful book.

The title is clearly derived from Garrod's original concept of "inborn errors of metabolism" and it is probably not too fanciful to surmise that the next edition will come with a pullout wall chart linking all the known molecular developmental cascades in the sort of multidirectional interrelated nightmarish diagram that is much beloved of biochemists. For the moment readers will have to suffice with accounts of individual pathways and gene families. Not that they should feel deprived, for this is a very impressive review of the state of the art.

The editors have divided the 108 chapters into four main sections covering patterns of development, defined developmental pathways, gene families not yet in pathways, and regulatory processes. Each chapter is roughly equally divided between molecular biology and "syndromology", with valiant attempts to make plausible links between cause and effect. Inevitably some chapters score more highly than others but I would be hard pressed to find fault with any of the many chapters consulted during a busy six weeks of clinical practice. However it was a little surprising to find that some topical conditions such as Seckel's, Sotos's and Van der Woude's syndromes have not been included, and a few more illustrations would not go amiss. One particular chapter, which should perhaps remain anonymous, contains two solid pages of amino acid sequences without a single diagram or illustration to enlighten the reader
Overall it is difficult to see how this book can be faulted, representing as it does the collective wisdom of three erudite editors, 188 distinguished authors, and a generation of outstanding scientists and clinicians. Together with the latest edition of Gorlin's Syndromes of the head and neck, this provides the definitive guide to molecular and clinical dysmorphology. It's not cheap but no genetics library worthy of the name can afford to be without it.

I D Young

\section{The genetics of renal disease}

Edited by F Flinter, E R Maher, A Saggar-Malik. Oxford: Oxford University Press, 2003, £120.00 (hardback), pp 568. ISBN 0192631462

"The kidney inspires awe in all those who attempt to understand its functions." This first sentence of chapter 2 of The genetics of renal disease perfectly captures the spirit of this book. Inherited renal disease is one of the most diverse, fascinating, and quickest growing areas of human genetics. Functional analyses of the genes associated with renal disease are leading to connections with many other scientific fields. For example, as is beautifully illustrated in colour plate 5 in this book, proteins now known to be directly involved in genetic renal disease are linked to the actin cytoskeleton, the endothelium, and basic cellular processes studied by laboratories not necessarily involved in renal disease.

The genetics of renal disease contains everything you might expect based on its title, and also some surprises. In the category of things you would expect are chapters devoted to each of the major genetic renal diseases, including Alport's syndrome, cystinosis, autosomal dominant polycystic kidney disease, autosomal recessive polycystic kidney disease, tuberous sclerosis complex, and von Hippel Lindau disease. An important feature is the broad scope of each chapter, most of which encompass aetiology and pathophysiology as well as clinical management. For example, the chapter on autosomal dominant polycystic kidney disease by Saggar-Malik and Somlo includes animal models of polycystic kidney disease, functional analyses of the PKD1 and PKD2 genes and proteins, mutation detection, and a flow diagram for the clinical evaluation of suspected intracranial aneurysm in autosomal dominant polycystic kidney disease. The chapter on autosomal recessive polycystic kidney disease by Guay-Woodford discusses animal and cell culture models, prenatal diagnosis, and clinical management. The chapter on von Hippel Lindau disease by Maher discusses the function of the von Hippel Lindau disease protein, clinical and genetic diagnostic strategies, and the management of renal and extra-renal manifestations.
What are the surprises? The first surprise, and a highlight of the book, is the third chapter, which is by Paul Winyard, and is titled "Renal development". This provides a comprehensive yet readable summary of a complex field with relevance to the pathogenesis, and perhaps eventually the therapy, of many renal diseases. The first and second chapters are introductions to clinical genetics and renal physiology, respectively. These will be helpful to non-specialists.

A second surprise is the very complete chapter, written by Gough and Vile, on gene therapy for renal cancer, which provides a potential framework for gene therapy for other forms of renal disease. Perhaps future books of similar scope will be able to include chapters devoted to targeted small molecule therapies and renal regenerative therapy.

A third surprise is the inclusion of genetically complex renal diseases such as glomerulonephritis and membranous nephropathy, and genetically complex systemic disorders affecting the kidney, including hypertension, diabetes, and systemic lupus erythematosus. The genetic data underlying these diverse diseases are elegantly summarised in a chapter by Powis. Elucidating the genetic basis of these disorders will be a major challenge of the next phase of renal genetics research.

In summary, this comprehensive yet accessible text links genetics, pathogenesis, and clinical management. The reader can rapidly locate a single piece of information using the index, efficiently review a topic by reading a few paragraphs, or acquire a comprehensive introduction to a disease by reading an entire chapter. The genetics of renal disease will have broad appeal to paediatric and adult nephrologists, clinical and laboratory based geneticists, and basic scientists, highlighting the increasingly interdisciplinary nature of renal disease research.

E P Henske

\section{CORRECTION}

doi: 10.1136/jmg.2003.011924corr 1

Two authors, M Halme and A RäisänenSokolowski, were inadvertently omitted in the paper by Harrison et al, published in December 2003 (J Med Genet 2003;40:865-71). The correct author sequence should therefore be: R E Harrison, J A Flanagan, M Sankelo, S A Abdalla, J Rowell, R D Machado, C G Elliott, I M Robbins, H Olschewski, V McLaughlin, E Gruenig, F Kermeen, M Halme, A Räisänen-Sokolowski, T Laitinen, N W Morrell, R C Trembath. The error is much regretted. 